\title{
DESEOS PERSONALES, INCLINACIONES NATURALES Y EL SIGNIFICADO DEL AMOR Michele M. Schumacher*
}

RESUMEN: Se analiza, en este texto, el conflicto que enfrenta la mujer entre el amor propio, guiado por la razón ilustrada, y el amor materno impulsado por inclinaciones naturales (el deber de la Madre Naturaleza) y sociales (la sociedad patriarcal). A partir de la crítica al argumento de Elisabeth Badinter se plantea el tema del amor, como consentimiento, aprobación o afirmación. El poder creativo de Josef Pieper apunta a que no hay necesidad para que surja el conflicto entre la felicidad de una mujer y su vocación maternal, entre el amor propio y el camino del amor.

\section{9ose \\ PERSONAL DEsires, NATURAL INCLINATIONS, AND THE MEANING OF LOVE}

ABSTRACT: In this article, we examine the conflict facing women between self-esteem, guided by enlightened reasoning, and maternal love driven by natural inclinations (Mother Nature's calling) and social ones (patriarchal society). Based on a criticism of Elisabeth Badinter's proposition, we present the subject of love as consent, approval, or affirmation. Josef Pieper's creative force shows us that there is no need for such conflict between women's' happiness and their maternal calling nor between self-esteem and the path to love.

PALABRAS CLAVE: Badinter, Pieper, deber, felicidad, amor materno, sociedad patriarcal. KEY WORDS: Badinter, Pieper, duty, happiness, maternal love, patriarchal society.

RECEPCIÓN: 28 de noviembre de 2013.

APROBACIÓN: 11 de febrero de 2015.

* Universidad de Friburgo. 
CITAM Derechos Reservados.

La reproducción total o parcial de este artículo se podrá hacer si el ITAM otorga la autorización previamente por escrito. 


\section{DESEOS PERSONALES, INCLINACIONES \\ NATURALES Y EL SIGNIFICADO DEL AMOR*}

Fergus Kerr escribió: “Quienquiera que haya estudiado filosofía moral durante las décadas de 1950 y 1960 recordará haber enfrentado una disyuntiva: utilitarismo o deontología. Ya fuere John Stuart Mill o Kant, el curso correcto para la acción se decidía bien al calcular el beneficio para otros, bien al considerar el deber propio". ${ }^{1}$ Dentro del contexto de parámetros asaz limitados, no debe sorprender que los deseos resultaran sospechosos a ojos de los moralistas. En el marco utilitario, amenazaban con enfrentar al individuo contra su prójimo al colocar los intereses de uno contra el otro. En el contexto de la deontología, resultan igualmente amenazadores al confrontar la "vil" naturaleza contra la razón "ilustrada". En ambos casos, claramente dan muestra del ímpetu hacia el amor generoso. Pero en ambos casos, se pierde la noción de que los deseos (en cuanto que precisamente son expresión de una naturaleza dada por Dios) pudieran brindar impulso a la virtud, pues "naturalmente" nos conducen al fin para el cual fuimos creados (la felicidad humana). En su lugar, se perpetúa el conflicto entre el amor propio y el amor al otro, que únicamente se puede resolver a través del sacrificio de uno mismo o del prójimo. ${ }^{2}$

* Traducción de Mauricio Sanders.

${ }^{1}$ Fergus Kerr, After Aquinas: Versions of Thomism, 2002, Alden, MA, Oxford y Victoria, AS, Blackwell, p. 115.

${ }^{2}$ Para mayores detalles, veánse Servais Pinckaers, The Sources of Christian Ethics, 1995, 1995, Washington DC, CUA Press, traducción de Sor Mary Thomas Noble, en especial pp. 240-53 
Particularmente ilustrativo en el caso de este conflicto (por un lado entre el utilitarismo y la deontología; por otro, entre el amor propio y el amor al prójimo) es lo que la filósofa francesa Elisabeth Badinter recientemente ha presentado como el "conflicto" entre "la mujer", guiada por la razón y la voluntad de decidir en ausencia tanto de inclinaciones naturales como de presiones sociales, y "la madre", que sucumbe al llamado del deber anunciado por la Madre Naturaleza y una sociedad patriarcal. Badinter, quien recientemente ha sido aclamada en Francia como "la intelectual más influyente"3 y "la voz más prominente en temas feministas", ${ }^{4}$ obviamente alienta a "la mujer" en su lucha contra "la madre". Por mi parte, me abstengo de elegir entre las dos, puesto que estoy convencida de que las premisas del argumento de Badinter están equivocadas desde el principio.

Para defender mi postura, en la primera parte expondré el argumento de Badinter, para después argumentar a favor de un deseo maternal natural, el cual (lejos de ser una inclinación o instinto animal, como lo entiende Badinter), como lo diré, es propio de la mujer en tanto ser racional. En la tercera parte (después de haber aclarado ciertos malentendidos acerca del significado del deseo en la segunda parte) sostendré que dicha inclinación debe ser comprendida en términos del amor de una mujer por sus hijos o del deseo de amar a unos niños a quienes apenas alcanza a imaginar que serán suyos. Ciertamente que esta inclinación natural al amor no debe ser entendida (y en esto estoy por completo de acuerdo con Badinter) en términos de un espíritu naturalmente masoquista o abnegado propio de la mujer en cuanto hembra, sino, como lo veremos en la cuarta parte, como una afirmación espontánea del

y 327-53; e idem, Morality: The Catholic View, 2001, South Bend, IN, St. San Agustíne's Press, prologado por Alasdair MacIntyre y traducido por Michael Sherwin, pp. 65-81; Michael Sherwin, "Happiness and Its Discontents", Logos: A Journal of Catholic Thought and Culture, 2010, 13: 4, pp. 35-59; Albert Plé, Par devoir ou par plaisir, 1980, París, Cerf. Para poner la tensión en contexto, véase Micheal Allen Gillespie, Los orígenes teológicos de la modernidad, 2008, Chicago, University of Chicago Press; y Louis Dupré, The Enlightenment and the Intellectual Foundations of Modern Culture, 2004, New Haven y Londres, Yale University Press.

${ }^{3}$ Encuesta CSA-Marianne 2010. Véase "Têtes, la star des intellos", La Liberté, 2010, Friburgo, Suiza, 12 de octubre, p. 2.

${ }^{4}$ Véase "Picking a Fight with Motherhood", International Herald Tribune, 7 de junio de 2010 . 
bien intrínseco que representan los niños. ${ }^{5}$ En consecuencia, pudiera afirmarse que el amor espontáneo de una madre por sus hijos no solo precede sino que incluso motiva su deseo de ser madre. ${ }^{6}$ En otras palabras, pudiera pensarse que sus deseos (más que ser pura casualidad) están orientados desde el comienzo hacia ciertos bienes y fines: un niño o unos niños, en el caso que nos ocupa. A su vez, esto implica que los deseos no tienen por qué ser caprichosos ni tienen que estar limitados a lo subjetivo o lo tajante. En cambio, de manera más positiva puede considerarse que son receptivos y por tanto objetivos. ${ }^{7}$ Por último, tras haber argumentado a favor de lo que Josef Pieper llama el poder creativo del amor humano, concluiré en la quinta parte que no hay necesidad para que surja un conflicto entre la felicidad de

${ }^{5}$ Esto no significa la negación del pecado original por causa del cual los niños quedan "privados de su santidad y justicia originales, [...] sujetos a la ignorancia, el sufrimiento y el dominio de la muerte; e inclinados al pecado, como lo enseña el catecismo de la Iglesia católica (núm. 405). No obstante, el catecismo también enseña que no por ello "la naturaleza humana no ha sido completamente corrompida" ( bid.). Por tanto, sugiero que acudamos al principio tomista que dicta que el bien es "coextensivo al ser". Sin embargo, sigue en pie una diferencia: "Lo que el bien añade al ser es una referencia al deseo o al apetito: algo deseable no es sino un ser considerado como objeto de deseo" (David M. Gallagher, "Goodness and Moral Goodness" en idem (ed.), Thomas Aquinas and His Legacy, 1994, Washington DC, CUA Press, pp. 37-60, aquí p. 41).

${ }^{6}$ Como tal, esta manera de comprender es compatible con el modo en que Daphne de Marneffe presenta el deseo maternal: "Es la nostalgia que una madre siente por alimentar a sus hijos; el deseo de participar en la relación entre ambos; y, en la medida de lo posible, la decisión de poner en práctica sus deseos". Más específicamente, ella nos instruye diciendo que "el auténtico deseo de ser madre que siente una mujer, deseo que no se deriva de la necesidad del hijo, aunque responde a este; un deseo que no es creado a través de una función social, aunque potencialmente apoyada en esta; más bien, un deseo anclado en la experiencia de su propio ser como un agente, un individuo autónomo, una persona". Daphne de Marneffe, Maternal Desire: On Children, Love and the Inner Life, 2004, Nueva York, Boston, Back Bay Books, Little, Brown y Company, pp. 3 y 4.

${ }^{7}$ Como ya lo he afirmado en otro lugar: "Primero que nada, me dirijo interiormente (o subjetivamente) hacia eso que (o ese a quien) deseo instintiva o apasionadamente, o más noblemente, hacia eso que (o ese a quien) de manera consciente (esto es, de manera racional) estimo como bueno y por tanto deseable. En segundo lugar, al mismo tiempo (por tanto la prioridad no es temporal sino ontológica) me dirijo exteriormente (u objetivamente), por así decirlo, a causa de una atracción real cuya fuerza estriba menos en mí que en la bondad natural de la persona o cosa a la que amo" (Michele M. Schumacher, "Feminism, Nature and Humanae Vitae: What's Love Got to Do with It?", Nova et Vetera, edición en inglés, 6:4, otoño de 2008, p. 886). 
una mujer y su vocación (o "función”, de acuerdo con Badinter) maternal, entre el amor propio y el auténtico amor al otro, entre el camino natural (entendido correctamente) y el camino del amor.

\section{El conflicto de Badinter}

Elisabeth Badinter ciertamente que no es nueva en la escena que acabamos de describir. Esta feminista septuagenaria, erudita en humanidades, filósofa y empresaria también es autora y editora de más de veinte libros, "batalla" por la libertad y autodeterminación de las mujeres. Habiendo sido testigo del "giro de 180 grados del feminismo", 8 ocurrido en un lapso de aproximadamente diez años y que fue desde el énfasis que Simone de Beauvoir ponía en la igualdad de los sexos hasta la eliminación de las diferencias llevada a cabo por el feminismo esencialista que considera a la femineidad tanto una "esencia" como una "virtud", ${ }^{9}$ Badinter claramente nos invita a regresar a una "edad dorada" en la que se anima a las mujeres a independizarse de su anatomía.

En aquellos primeros años que siguieron a Le deuxième sexe ( $E l$ segundo sexo), el famoso libro que De Beauvoir publicó en $1949,{ }^{10}$ la batalla de las mujeres en favor de su libertad se libró en dos frentes: por una parte, en contra de la naturaleza y el argumento del determinismo biológico (o la reducción de una mujer a eso que yace en el ámbito de su cuerpo y su funcionamiento); y por otra, en contra del determinismo cultural, o la presión para vivir según un ideal promovido a través de una cultura orquestada en buena medida por machos que buscan someter a la mujer para que ocupe el lugar que le corresponde

${ }^{8}$ Véase Elisabeth Badinter, Le conflit, la femme et la mère, 2010, París, Editions Flammarion, p. 83: "tête-à-queue du féminisme". Traducción al inglés de Adriana Hunter, 2011, Nueva York, Metropolitan Books / Henry Holt y Co.

${ }^{9}$ Véase ibid., p. 84.

${ }^{10}$ Véase Le deuxième sexe: I. Les faits et les mythes, II. L'expérience vécue, 1949, París, Gallimard. Traducción al inglés de H. M. Parshely, 1952, Alfred A. Knopf, Inc. y 1989, Nueva York, Vintage Books. 
en un mundo de varones. No obstante, Badinter observa que en el presente ambas fuerzas se han combinado para formar un solo enemigo formidable ante el cual se ha doblegado hasta el feminismo. Claramente, como lo hace notar Badinter, siempre ha sido del interés de la sociedad patriarcal afirmar que la naturaleza está de su lado. Tal como lo concibe Badinter, al presentar a la mujer como un ser creado para ser dócil, obediente y maternal no hace sino vestir al condicionamiento cultural con el disfraz del determinismo natural. No obstante, en el presente esta estratega de los derechos de la mujer ha detectado un peligroso cambio en el campo de batalla. Ahora parece como si la naturaleza llevara la voz cantante, reclutando para su estandarte tanto a los machos como a las feministas de talante esencialista: aquellas que recalcan las diferencias sexuales, en contraste con las feministas de la igualdad que, como Badinter, se basan en la semejanza. Badinter lamenta que las feministas esencialistas se hayan unido en torno a la ecología y a las ciencias humanas para proponer una ideología común que oprime a las jóvenes mujeres que ya son madres o quisieran serlo, ${ }^{11}$ bajo la divisa: "Una madre siempre sabe".

Téngase muy en cuenta que esta "Madre" omnisapiente no forma parte de la mujer, puesto que Badinter cree que ya dio cuenta del "mito" del instinto maternal en L'amour en plus, uno de sus libros anteriores traducido al inglés bajo el título de Mother Love, ${ }^{12}$ no obstante, Badinter admite (con cierta frustración) que este no deja de brotar una y otra

${ }^{11}$ El primer nombre que salta a la vista entre las feministas francesas es el de Luce Irigaray, aunque el argumento de Badinter está construido en oposición a Alicia Rossi, Carol Gilligan y Antoinette Fouque. Véase Elisabeth Badinter, Le conflit, pp. 83-92.

${ }^{12}$ Elisabet Badinter, L'amour en plus. Histoire de l'amour maternel, XVIIe à XXe siècle, 1980 y 2000, París, Flammarion (Mother Love: Myth and Reality, 1982, Nueva York, Macmillan Publishing). Para sus conclusiones acerca del instinto natural como mito, véase Mother Love, p. 327: "Al revisar la historia de las diferentes formas de conducta maternal nace la convicción de que el instinto maternal es un mito. No ha emergido una conducta absolutamente universal por parte de la madre [...] Todo depende de la madre, su historia y nuestra historia. No, no hay leyes universales sobre esta cuestión que trasciende al determinismo natural. El amor maternal no está dado. Cuando existe, es una ventaja adicional, un extra, algo que fue añadido al trato que cerraron algunos afortunados." Resulta particularmente interesante notar que esta última frase ("algo que fue añadido al trato que cerraron algunos afortunados") no aparece en la versión original en francés. Véase L'amour en plus, p. 439. Igualmente: "Las mujeres que se niegan a sacrificar sus esperanzas y ambiciones ante el bienestar de sus hijos son demasiado numerosas como para categorizarlas dentro de las excepciones patológicas que confirman la regla" (Mother Love, p. 307; L'amour en plus, p. 415). 
vez en la discusión pública. ${ }^{13}$ No, esta Madre omnisapiente es un enemigo más de la libre autodeterminación de las mujeres. Esta vez es la "bondadosa" Madre Naturaleza a quien Badinter ataca; pues es ella quien llama a un regreso al modelo tradicional de maternidad, ${ }^{14}$ que "obviamente" se opone a la emancipación conquistada para las mujeres por las feministas bajo la influencia de Simone de Beauvoir. Para ser más específicos, esta Madre "omnisapiente" oprime a las pobres madres humanas por medio de sus "buenos" consejos: parto natural, ${ }^{15}$ lactancia pródiga, ${ }^{16}$ cercanía física durante la crianza (de ser posible de "piel a piel"), ${ }^{17}$ pañales de tela o biodegradables, ${ }^{18}$ dormir con el bebe, ${ }^{19}$ completa abstinencia de alcohol durante el embarazo ("tolerancia cero") ${ }^{20}$ y lo mismo con el tabaco (incluso después del embarazo), ${ }^{21}$ por no decir nada de las relaciones sexuales. Sobre esto último, Badinter no puede sino señalar con sarcasmo que la "buena" Madre Naturaleza aconseja a sus hijas no solamente a que duerman con sus criaturas, sino a que den prioridad a la relación entre madre e hijo por encima de su relación de pareja. ${ }^{22}$

En suma, en el regreso de naturalismo Badinter ve la "dulce tiranía de los deberes maternales", en la cual colabora "el bebé inocente" que "muy a pesar de sí mismo" se convierte en "el mejor aliado de la dominación masculina". ${ }^{23}$ De hecho, el poder de esta "beatífica" Madre Naturaleza ha llegado a cobrar tanta influencia en el presente que Badinter no puede sino preguntarse: “¿Qué madre no experimenta por lo menos un toque de culpa si deja de conformarse con las leyes de la naturaleza?" ${ }^{24}$ Como denuncia de todo este tradicionalismo retrógrada,

${ }^{13}$ Véase como ejemplo Le Conflit, pp. 68-83.

${ }^{14}$ Véase como ejemplo ibid., p. 13.

${ }^{15}$ Véase como ejemplo ibid., pp. 58-65.

${ }^{16}$ Ibid., pp. 65-6, 101-26.

${ }^{17} \mathrm{Ibid}$., por ejemplo, su forma de tratar la teoría de los vínculos ("la théorie du lien"), ibid, pp. 70-7, p. 80.

${ }^{18}$ Ibid., pp. 66-8.

${ }^{19}$ Ibid., p. 153: "cododotage“ (dormir con el bebé).

${ }^{20}$ Ibid., p. 97.

${ }^{21}$ Ibid., pp. 97-101.

${ }^{22}$ Ibid., pp. 152-9.

${ }^{23} \mathrm{Ibid}$., p. 146. Véase también ibid., p. 145; e idem, Mother Love, p. 4; L'amour en plus, p. 28.

${ }^{24} \mathrm{Ibid}$., p. 93: "Quelle mère n'éprouvera pas, au minimum, un pincement de culpabilité si elle ne se conforme pas aux lois de la nature?". 
Badinter llega a conjeturar lo siguiente: "Como Rousseau en su época (1712-1778), uno podría convencer a las jóvenes madres para que se unan con la naturaleza y vuelvan a los principios, con el cimiento construido sobre el instinto maternal. No obstante, a diferencia de lo que ocurría en el siglo XVIII, las mujeres de hoy tienen tres posibilidades en cuanto a la primacía que confieren a su función maternal por encima de su interés personal: adherirse, negarse o negociar". ${ }^{25}$

Así es que Badinter nos hace abrir los ojos ante lo que considera un condicionamiento social disfrazado de condicionamiento natural (o biológico), para que en nosotras llegue a despertar la voluntad de alzarnos por encima del nivel de las inclinaciones propias de la animalidad (prerracionales) y de esa manera poder aceptar o rechazar la maternidad pero de forma racional. Siguiendo el hilo de su razonamiento, Badinter dice que esto a su vez implica que las mujeres puedan discernir una ética de coerciones y obligaciones que se basa en la identificación entre lo natural y lo bueno, ética que subyace a los consejos actuales al tenor de "una madre siempre sabe". No obstante, Badinter pregunta con insistencia en qué se puede basar la identificación entre lo bueno y lo natural sino en lo que ella considera como un escándalo. Después de todo, tal como lo argumenta en su libro anterior, "afirmar que la naturaleza hace las cosas bien no puede ser admitido sin dificultad. Sus obras no carecen de defectos. Para resultar convincente, uno debe esforzarse mucho en elaborar una defensa que, para muchos, es también la de Dios. Todo el problema consiste en demostrar que vivimos en el mejor de los mundos posibles lo cual, después de todo, no resulta evidente". ${ }^{26}$

${ }^{25}$ Ibid., p. 13: "Cette idéologie qui prône tout simplement un retour au modèle traditionnel pèse de tout son poids sur l'avenir des femmes et sur leurs choix. Comme Rousseau en son temps, on veut aujourd'hui les convaincre de renouer avec la nature et de revenir aux fondamentaux dont l'instinct maternel serait le pilier. Mais à la différence du XVIIe siècle, elles ont aujourd'hui trois possibilités: adhérer, refuser ou négocier, selon qu'elles privilégient leurs intérêts personnels ou leur fonction maternelle." Acerca de la filosofía de Rousseau, véase idem, Mother Love, pp. 30, 134-142, 166, 180-183, 186, 201, 208-216 [L'amour en plus, pp. 60, 127, 193-203, 235, 252-255, 260, 279, 287-298]; e idem, Le Conflit, pp. 251-252.

${ }^{26}$ Elisabeth Badinter, Prefacio (Avant propos), con fecha de julio de 1981, a L'amour en plus, pp. 16-17: "Idée qui renvoie à une philosophie finaliste, laquelle trouve son achèvement dans une théodicée, même lorsqu'elle ne s'avoue pas. Car, dire que la nature fait bien les choses ne va pas sans difficulté. Son ouvrage n'est pas sans défaut. Et pour convaincre, il faut plaider durement 
Por supuesto que no es evidente, en tanto que Badinter piensa que en su obra clásica de 1980, Amour en plus (Mother Love) dejó probado que multitud de madres francesas de los siglo XVII y XVIII estaban dispuestas a sacrificar las vidas de sus hijos recién nacidos confiándolos a la nodriza, incluso a sabiendas (así lo cree Badinter) de que sus probabilidades de sobrevivir, de por sí relativamente bajas, quedaban en un riesgo significativamente mayor. A pesar de que la tasa de mortalidad entre los niños amamantados por nodrizas por lo general duplicaba la de niños que tomaban el pecho de su madre, "la mayoría de las madres no podían sino continuar con esa práctica cuando las necesidades de su propio trabajo hacían imposible la lactancia". ${ }^{27}$ Así es que Badinter concluye que "el sistema de nodrizas considerado de forma 'objetiva' no era sino una forma disfrazada de infanticidio". ${ }^{28}$

A decir verdad, Badinter acepta que esta situación comprende más elementos que la importante función social de la mujer, que incuestionablemente se ve afectada cuando se tiene que alimentar a un lactante. Las presiones culturales también ejercieron una fuerte influencia en favor del "vínculo familiar", ${ }^{29}$ el cual según médicos y moralistas se veía amenazado por la abstinencia sexual prolongada, que se recomendaba tanto durante el embarazo como en la lactancia. ${ }^{30}$ ¿Pero qué sucedía con aquellas madres que, cuando el niño destetado volvía al hogar familiar, rápidamente lo confiaban a una instituriz y enviaban al niño a un internado? ${ }^{31}$ ¿Y más aún, qué pasaba con "las tramposas" (le tricheuses) $)^{32}$ quienes, más tarde, bajo la fuerte influencia de Jean-Jacques Rousseau, se quedaban en casa con los recién nacidos y los infantes, presumible-

sa cause qui est, pour beaucoup, celle de Dieu. Tout le problème consiste à démontrer que nous vivons dans le meilleur monde possible, ce qui, après tout, n'est pas évident." Curiosamente, este prefacio no aparece en la versión en inglés que apareció ese mismo año.

${ }^{27}$ Idem., Mother Love, p. 113 [L'amour en plus, p. 166]. Véase también ibid., p. 109ss.

[p. 159ss.]; idem, Le Conflit, 244-5.

${ }^{28}$ Idem, Mother Love, p. 112 [L'amour en plus, p. 164].

${ }^{29}$ Idem, Le Conflit, p. 242: "la cohésion familial"; cfr. idem, Mother Love, p. 70 ss. [L'amour en plus, 110ss.].

${ }^{30}$ Se pensaba que el esperma estropeaba la leche materna. Véase idem, Mother Love,

p. 70 [L'amour en plus, p. 110]; idem, Le Conflit, p. 242.

${ }^{31}$ Véase idem, Mother Love, pp. 103-108 [L'amour en plus, pp. 147-59].

${ }^{32}$ Ibid., p. 196 [p. 273]. 
mente teniéndolos bajo su "amoroso cuidado", aunque contrataban en el campo a madres pobres que abandonaban a sus propios bebés para ir a trabajar de nodrizas en las casas ricas? Y para que se acabe de romper el corazón, ¿qué pasaba con aquellas mujeres pobres casi en el puerperio todavía, que de muy buena gana (según Badinter) abandonaban a sus hijos recién nacidos para ir a cuidar a los hijos de las mujeres adineradas? $?^{33}$ Badinter se pregunta por qué, incluso cuando estaban afligidas por la pobreza extrema, no esperaban por lo menos a que sus hijos contaran con algunos meses de edad antes de entregarse a su labor de mercenarias.

¿Acaso no podríamos conjeturar, incluso si por precaución debiéramos evitar todo juicio definitivo, que estas mujeres ponían sus propias vidas e intereses por encima de los de sus hijos, lo cual demostraría que la devoción todavía no era un valor arraigado, ni siquiera en una sociedad que lo proclamaba en voz alta como un hecho natural? ¿Y qué con esa sociedad hipócrita que al mismo tiempo celebraba las virtudes de la ama de casa feliz y ensalzaba a los niños pero al mismo tiempo cerraba los ojos ante la falsedad de unas y el sufrimiento verdadero de las otras? ${ }^{34}$

De hecho, Badinter está convencida de que a falta de una presión social en sentido contrario, las mujeres claramente prefieren y buscan su propio desarrollo por encima del bien de sus hijos, incluso cuando puedan poner en riesgo la vida de estos.

Ni la pobreza ni la ignorancia explican estos infanticidios, tan solo la indiferencia, que prácticamente hasta finales del siglo XVIII no era mal vista, pues no se consideraba que fuera en violación de los códigos morales o sociales. Este último punto es fundamental, pues parece indicar que, a falta de una presión externa como esta, la madre quedaba libre para actuar conforme a su propia naturaleza, una naturaleza egoísta que excluía hasta la traza más minúscula de autoinmolación por el bien del niño que acababa de traer al mundo. ${ }^{35}$

${ }^{33}$ Badinter señala una tasa de mortalidad entre 64 y 87. Véase ibid., p. 197 [p. 274].

${ }^{34}$ Ibid., p. 199 [L'amour en plus, p. 277].

${ }^{35}$ Ibid., pp. 113-114. [L'amour en plus, pp. 166-7]. 
Habiendo pues destruido (o creyéndolo así) el "mito" de un instinto maternal natural, hace treinta años que Badinter fue en pos de su siguiente objetivo, presentado en un libro que pretendía salvar a las mujeres de la imagen cultural construido sobre el mito de la "buena madre". Badinter argüía que no es necesario ser una "madre" así, pues si alguien quisiera apegarse a este ideal no hubiera podido llegar a ser madre en primer lugar. La maternidad contemporánea, que se debe a los anticonceptivos y los abortos fácilmente asequibles, se ha transformado en una cuestión de elección, ${ }^{36}$ lo cual resulta en un verdadero predicamento: por un lado, nuevos considerandos acerca de las "obligaciones con respecto al niño a quien se decidió traer al mundo"; por el otro, la elevación "hasta un nivel de primacía de la noción de superación personal". ${ }^{37}$ Tales son los términos en que Badinter plantea "el conflicto" de las mujeres de nuestros tiempos, quienes se encuentran a merced de un conflicto aún mayor entre naturalismo, con sus propias obligaciones y restricciones éticas favorecidas por el patriarcado, y el hedonismo, al cual Badinter considera como el medio auténticamente humano para el desarrollo personal. ${ }^{38}$ "A decir verdad, el naturalismo no conoce peor enemigo que el individualismo hedonista", ${ }^{39}$ que "busca placer sin dolor". ${ }^{40}$ De hecho, desde el punto de vista de Badinter, si las mujeres actualmente todavía escogen ser madres, se debe únicamente a que consideran que así contribuyen a su propia satisfacción o placer. ${ }^{41}$

Por tanto, Badinter señala un tanto al desgaire que actualmente las mujeres eligen un "instinto" por encima del otro; por una parte, el llamado instinto maternal, asignado por el naturalismo a las mujeres en virtud a una "naturaleza" femenina particular, y por la otra, el instinto, impulso o apetito de placer. En consecuencia, la opción fundamental que nos presenta es: la satisfacción personal en términos de un placer egoísta,

${ }^{36}$ Véase Elisabeth Badinter, Le conflit, pp. 9, 31, 188, 229.

${ }^{37} \mathrm{Ibid}$., p. 10: “devoirs accrus à l'égard de l'enfant que l'on choisit de faire naître;" "elle place au premier plan la notion d'épanouissement personnel." Badinter admite: "El escoger ser madre no garantiza, como se pensaba en el principio, una mejor maternidad" (ibid., p. 28: "Choisir d'être mère ne garantit pas, comme on l'a cru au début, une meilleure maternité").

${ }^{38}$ Véase ibid., pp. 24-5.

${ }^{39} \mathrm{Ibid}$., p. 252: “En vérité le naturalisme n'a pas de pire ennemi que l'individualisme hédoniste".

${ }^{40} \mathrm{Ibid}$., p. 253: "veut les plaisirs sans les peines".

${ }^{41}$ Véase como ejemplo ibid., pp. 10, 22. 
característico de "la mujer", o el sacrificio que caracteriza a "la madre"; la plenitud de la mujer o su acabamiento.

Con semejante planteamiento, uno bien puede preguntarse quién si no una mártir podría escoger voluntariamente la maternidad. No obstante, Badinter no sugiere que abandonemos la maternidad, sino el "martirio": vivir para nuestros hijos o vivir para nosotras mismas. En otras palabras, este duro contraste (la "mujer" o la "madre" mártir) sirve particularmente para el propósito de despertar en las mujeres el deseo de tomar decisiones racionales, para que así podamos ir más allá de nuestros deseos y ponernos al servicio de lo que ella considera es nuestro legítimo interés. ${ }^{42}$ Así es que el argumento de Badinter sugiere que nuestros deseos, puesto que son prerracionales, son también irracionales. Por tanto, muchas de nuestras decisiones son meras ilusiones, que surgen "en buena medida de lo afectivo y lo normativo considerado social o culturalmente, más que de un análisis racional de ventajas e inconvenientes" ${ }^{43}$ Por dar un ejemplo, propone una encuesta nacional realizada en Francia, dando una interpretación (en mi opinión, falsa $)^{44}$ según la cual dicha

${ }^{42}$ Véase como ejemplo ibid., p. 25.

${ }^{43}$ Le conflit, p. 22: "premier rang des motivations"; "l'hédonisme [...] sans qu'il ne soit jamais question de sacrifices et de don de soi"; "la décision découle plus largement de l'affectif et du normatif que de la prise en compte rationnelle des avantages et des inconvénients".

${ }^{44}$ Tal es la conclusión a la que llega a partir de las siguientes respuestas: "Un niño trae más hermosura y alegría a la vida cotidiana"; "Esto permite a la familia continuar, transmitir sus valores, su historia"; "Un niño trae cariño y amor y hace que la soledad de la vejez sea menor"; "Intensifica y consolida la relación de pareja"; "Ayuda para llegar a ser adulto y aceptar responsabilidades"; etc. (ibid., p. 21: "Un enfant rend la vie de tous les jours plus belle et plus joyeuse"; "Cela permet de faire perdurer sa familler, de transmettre ses valeurs, son histoire"; "Un enfant donne de l'affection, de l'amour et permet d'être moins seul quand on vieillit"; "Cela rend plus intense e plus solide la relation de couple"; "Cela aide à devenir adulte, à prendre des responsabilités", etc.) Me parece que todas estas razones son compatibles con lo que presentaré como la motivación del amor, especialmente cuando el amor se entiende como una afirmación del bien intrínseco que significa un hijo. En otras palabras, lejos de competir con afirmaciones sobre el valor intrínseco (el bien) de un hijo, tales referencias al placer (o deleite) que suscita un niño en la familia (e incluso fuera de esta) pueden ser considerados como la confirmación de su bondad intrínseca. Esto significa que no son nuestros deseos lo que nos hacen amar al niño, sino que nuestros deseos responden al hecho de que los hijos son amables. Por tanto, estos deseos no solamente "están completamente "en orden", sino que también son "el comienzo indispensable de la perfección en el amor [...] Lo que es más, toda la felicidad humana (que deseamos por instinto, aunque no necesariamente de forma egoísta, y por tanto con una conciencia legítimamente limpia) no es sino la felicidad del amor" (Josef Pieper, "On Love", 
encuesta revela que "la primera ronda de motivos" para concebir un hijo es el "hedonismo [...] sin que intervengan factores como el sacrificio o la donación del propio ser".

Entonces, el verdadero problema desde el punto de vista de Badinter (esto es, una vez que nos deshicimos de los condicionamientos sociales) radica en nuestros propios deseos. Por supuesto que hay que seguirlos, según ella razona, pero en la medida en que se conformen con nuestros principios hedonistas, los cuales irónicamente ella no cuestiona; no obstante, con demasiada frecuencia esos deseos no hacen sino conducirnos por el camino opuesto: "La futura madre fantasea con el amor y la felicidad. No sabe que del otro lado de la maternidad la esperan el cansancio, la frustración, la soledad, incluso la alienación con su desfile de culpas". ${ }^{45}$

Vale la pena repetir que, a pesar de tan poderosa disuasión, Badinter (quien es madre de tres) no afirma llanamente que deberíamos dejar de tener hijos. Más bien sugiere que los niños deberían ser escogidos en forma racional de acuerdo con el programa o estilo de vida que cada quien haya elegido libremente. ${ }^{46}$ Por otro lado, también advierte a las mujeres jóvenes para que no se adentren a ciegas en la "trampa" de la maternidad, que no tiene salida: "Reconocer que se ha cometido un error, que una no fue hecha para ser madre, y que obtiene muy poca satisfacción al serlo, es tanto como hacer de una misma una suerte de monstruo irresponsable". ${ }^{47}$ En consecuencia: "Haber elegido ser madre no garantiza una mejor maternidad, como antes se pensaba, no solamente porque la libertad de elección puede no ser más que un cebo, sino porque incrementa considerablemente el peso de las responsabilidades

traducción de Richard y Clara Winston, en idem, Faith, Hope, Love, 1997, San Francisco, Ignatius Press, pp. 139-281, aquí pp. 223 y 224.

${ }^{45} \mathrm{Ibid}$., p. 25: "La future mère ne fantasme que sur l'amour et le bonheur. Elle ignore l'autre face de la maternité faite d'épuisement, de frustration, de solitude, voire d'aliénation avec son cortège de culpabilité".

${ }^{46}$ Vale la pena mencionar que la maternidad de Badinter no fue obstáculo para que escribiera nueve libros que le han ganado cierto renombre, como ya lo mencioné con anterioridad.

${ }^{47} \mathrm{Ibid}$., pp. 26-27: 'Reconnaitre que l'on s'est trompée, que l'on n'était pas faite pour être mère et qu'on en a retiré peu de satisfactions ferait de vous une sorte de monstre irresponsable". 
en el momento en que el individualismo y la 'pasión del ensimismamiento' son más poderosos que nunca", ${ }^{48}$

Al parecer, lo que Badinter postula es que aquello que las mujeres realmente desean no es tanto lo maternidad como tal (esto es, hijos), sino los placeres que estos nos conceden. Por tanto, cuando el placer se acaba o se ve rebasado por los sacrificios, las mujeres se desencantan rápidamente y entonces deben admitir que han sido defraudadas por expectativas vanas, a su vez reforzadas, según sugiere Badinter, por una noción idealista de la maternidad instigada por naturalistas, feministas de la corriente esencialista y los vestigios (así lo espera Badinter) del patriarcado y sus machos. ${ }^{49}$ En esta situación, ¿qué puede hacer una pobre mujer?

Dado el gran peso de las responsabilidades que entraña la maternidad (por lo menos en términos de las expectativas sociales), Badinter nos conmina a tomar decisiones meditadas a favor o en contra de la maternidad a la luz de "los placeres y los dolores, los beneficios y los sacrificios" y en términos de nuestra "capacidad altruista". ${ }^{50}$ En suma, puesto que somos libres para decidir en favor o en contra de la maternidad, debemos decidirnos racionalmente. A su vez, esto implica que debemos considerar cuidadosamente si se conforma o no con nuestro más profundo deseo subjetivo de superación en forma de placer maximizado. Y para Badinter esto significa (y este es uno de los mayores factores en mi desacuerdo con sus razonamientos) que la maternidad racional (la maternidad especialmente escogida por su capacidad para aumentar el propio placer) se opone a la maternidad natural (la mater-

${ }^{48}$ Ibid., p. 28: "Choisir d'être mère ne garantit pas, comme on l'a cru au début, une meilleure maternité. Non seulement parce que la liberté de choix est peut-être un leurre, mais aussi parce qu'elle alourdit considérablement le poids des responsabilités en un temps où l'individualisme et la 'passion de soi' n'ont jamais été si puissants".

${ }^{49}$ Sobre este tema, véase también Susan J. Douglas y Meredith W. Michaels, The Mommy Myth: The Idealization of Motherhood and How it Has Undermined Women, 2004, Nueva York, etc., Free Press; Miriam Peskowitz, The Truth Behind the Mommy Wars: Who Decides What Makes a Good Mother?, 2005, Emeryville, CA, Seal Press; y Susan Maushart, The Mask of Motherhood: How Becoming a Mother Changes our Lives and Why We Never Talk about It, 2000, Middlesex, Inglaterra, Penguin Books.

${ }^{50}$ Ibid., p. 25: "des plaisirs et des peines, des bénéfices et des sacrifices"; "capacité altruiste." 
nidad que se escoge a causa de la presión social y bajo los ensalmos de los naturalistas y el patriarcado).

\section{Para aclarar malentendidos acerca de los deseos naturales}

Por supuesto, no cualquiera estaría de acuerdo en que para lograr la superación personal se debe maximizar el placer, y muy a menudo la escuela de feminismo a la Badinter ha conseguido liberar a las mujeres del "tedio" de las labores domésticas y la crianza de los hijos para entregarlas a la fábrica, la oficina o la empresa. Y mientras de buena gana denuncia diversas formas de condicionamiento cultural planteadas por una imagen idealista de la maternidad, irónicamente ella se congratula de la corriente cultural del presente, representada por el individualismo y el hedonismo. No obstante, la mayor objeción al argumento de Badinter (que a continuación iré desarrollando) es la falta absoluta de referencias a una palabra de cuatro que letras que, según creo, para la mayoría de nosotras constituye la razón de mayor peso y la más significativa para escoger la maternidad (o, en su caso, la paternidad) $:^{51}$ se trata del amor. No puedo hacer más que preguntarme por qué alguien querría ser madre, si no es por amor.

Al responder a pregunta tan importante, quizá convenga aclarar primero cierto número de importantes malentendidos en torno a nuestros deseos. Con demasiada frecuencia se asume que quienquiera que se encuentre en la posición de una mujer que naturalmente se siente atraída por los niños o que naturalmente desea ser madre es porque de hecho ya cayó en la trampa del reducccionismo biológico:

${ }^{51}$ Aunque es posible sostener idéntico argumento en el caso de los varones, con mucha razón Badinter arguye que en el caso de las mujeres hay mucho más en juego. Así lo expresa el papa Juan Pablo II: "la paternidad, sin bien pertenece a la mujer tanto como al varón, se cumple más plenamente en la mujer, especialmente en periodo prenatal. La mujer es quien 'paga' directamente por la generación compartida, que literalmente absorbe las energías de su cuerpo y de su mente. Por tanto, es necesario que el varón esté plenamente consciente de que en la paternidad compartida adquiere una deuda especial hacia la mujer. Ningún programa de 'igualdad de derechos' entre varones y mujeres sería válido si no considera todas las implicaciones de este hecho" (Carta apostólica sobre la dignidad y la vocación de las mujeres, Mulieres Dignitatem, agosto de 1988, núm. 18). 
esta suposición (basada en observaciones empíricas según las cuales las mujeres están orientadas biológicamente para concebir y criar niños, tanto por sus facultades físicas como por los deseos suscitados por sus hormonas) lleva a la conclusión de que las mujeres tienen la obligación ética de ser madres, por lo menos si desean cumplir con su destino y alcanzar la plenitud. De aquí que surja una pregunta: ¿cómo podría ser de otra manera, puesto que la naturaleza ha delineado la perfección en estos términos? Claramente, el naturalismo, en contraste con la teoría de la ley natural, que tradicionalmente se ha constituido como la enseñanza moral católica dominante, ${ }^{52}$ reduce a la naturaleza (la llamada naturaleza femenina inclusive) a su mínimo común denominador: lo físico, material o biológico. Por tanto, los naturalistas proponen que lo más natural es lo que perfecciona, aunque (y es aquí donde radica el problema) se toma a lo natural, incluso en el caso de los seres naturales, como aquello que yace estrictamente fuera del dominio de la razón. En consecuencia, se arguye, por ejemplo, que habiendo sido la mujer creada con la facultad para concebir y criar niños, también está provista de una suerte de instinto maternal, frase que pretende indicar que posee una propensión natural, una inclinación que la arrastra de forma irresistible hacia la maternidad como vía para lograr la propia perfección, de manera no muy diferente de un planeta que naturalmente gira en órbita. La razón está totalmente excluida de esta narrativa, por lo cual no resulta sorpresivo que las feministas la objeten. En cuanto a Badinter, legítimamente insiste en que "una mujer puede ser 'normal' sin ser madre, y no todas las madres sienten el impulso irresistible de cuidar a los hijos que ha dado a luz." 53

A modo de ilustración, Badinter señala un fenómeno observable en forma creciente en nuestros días (que corresponde al nuevo "poder" de las mujeres para negarse a la maternidad): las "emancipadas" " que

${ }^{52}$ Véase como ejemplo Juan Pablo II, Veritatis Splendor, núm. 47-50; y el catecismo de la Iglesia católica, 1954-1960.

${ }^{53}$ Elisabeth Badinter, Avant-propos a L'amour en plus, 9: "une femme peut être 'normale' sans être mère, et que toute mère n'a pas une pulsion irrésistible à s'occuper de l'enfant qui lui est né" (nuevamente, esto no aparece en la traducción al inglés, Mother Love).

${ }^{54}$ Véase idem, Le conflit, pp. 24, 31ss., 182-184, 210, 213, 229. Véase también Laura S. Scott, Two is Enough: A Couple's Guide to Living Childless by Choice, 2009, Berkley, CA, 
se distinguen de las "estériles": 55 mujeres que buscan emanciparse de la maternidad a favor de "satisfacciones conyugales y personales". ${ }^{56}$ Al regodearse en detalles horrendos acerca de la suerte malhadada de los niños de pecho franceses cuyas apáticas madres los abandonaban en brazos de una nodriza, Badinter ensalza el estilo de vida emancipado como algo mejor para los niños. Los lectores contemporáneos no pueden sino traer a colación atrocidades semejantes de nuestra época, entre las cuales destaca el aborto. ${ }^{57}$ Badinter hace este recuento de ejemplos para defender su postura de que el deseo natural de ser madre es "natural" solamente en el sentido de ser un impulso biológico coronado por un constructo social, y por tanto, no constituye una guía confiable para el desarrollo (ni de las madres ni de sus hijos). No obstante, el fenómeno empíricamente observable del maltrato infantil no implica por necesidad que el instituto maternal objetivamente "bueno" sea una mera ilusión. Así, por dar un ejemplo, de acuerdo con la perspectiva tomista de la ley natural los seres humanos son capaces de elegir entre diferentes deseos, ordenándolos según cierto número de factores, orientaciones o mentalidades: incluyendo tanto la orientación hacia el amor que trae auténtica plenitud, así como la orientación hacia el pecado que nos deshumaniza (como se observa en el caso del maltrato infantil). ${ }^{58}$

Seal Press; Corinne Maier, No Kids: 40 Good Reasons Not to Have Children, traducido del francés por Patrick Watson, Toronto, McClelland \& Stewart Ltd.; Jeanne Safer, Beyond Motherhood: Choosing a Life without Children, 1996, Nueva York, etc., Pocket Books; Susan S. Lang, Women without Children: The Reasons, The Rewards, The Regrets, 1991, Holbrook, MA, Adams Media Corporation; Elaine Tyler May, Barren and the Promised Land: Childless Americans and the Pursuit of Happiness, 1995, Cambridge, (MA) Londres, Harvard University Press; e Irene Reti (ed.), Childless by Choice: A Feminist Anthology, 1992, Santa Cruz, CA, HerBooks.

${ }^{55}$ Badinter pone como ejemplo a Francia, donde un tercio de las mujeres sin hijos aseguran haber tomado una decisión deliberada. Véase Le Conflit, p. 182.

${ }^{56} \mathrm{Ibid} .$, p. 215.

${ }^{57}$ La antropóloga Sarah Blaffer Hrdy hace el siguiente razonamiento: "Si las mujeres instintivamente aman a sus hijos, ¿cómo es que tantas mujeres de tan diversas culturas a través de tantas etapas históricas, de forma directa o indirecta, pueden haber contribuido a su muerte? ¿Cómo es que hay tantas mujeres que discriminan entre sus propios hijos, por ejemplo, alimentando al hijo mientras que la hija se muere de hambre?" (Mother Nature: Maternal Instincts and How They Shape the Human Species, 1999, Nueva York, Ballantine Books, p. xviii).

${ }^{58} \mathrm{Si}$ bien utiliza otras palabras, a esto es a lo que Daphne de Marneffe se refiere con justa razón como "la complicada arena donde compiten los deseos de las mujeres" (Daphne de Marneffe, Maternal Desire, p. 5). 
Para decir verdad, si bien la persona humana comparte apetitos, inclinaciones y deseos con los animales e incluso con seres inferiores, de manera que podemos distinguir tres órdenes de inclinaciones naturales ${ }^{59}$ (aquellas que compartimos con seres sin conocimientos sensibles, como la inclinación a preservar la existencia y por tanto a evitar peligros; aquellas que compartimos con otros animales, como la reproducción sexual y el cuidado de las crías; y aquellas que nos son propias en tanto que somos racionales, como conocer la verdad acerca de Dios y vivir en sociedad). No obstante, se dice que la razón las gobierna a todas, ${ }^{60}$ sin usurpar por ello la jurisdicción del Creador, claro está. ${ }^{61}$ Esta función de gobierno sobre el resto de las inclinaciones naturales se logra por medio de la voluntad, un apetito específicamente racional ("racional" puesto que naturalmente se inclina hacia aquello que le presenta el intelecto como verdadero y por lo tanto como bueno) ${ }^{62}$ que nos hace desear nuestra propia perfección que, como lo enseña el Aquinate, no es otra cosa que nuestra propia felicidad. ${ }^{63}$ Después de todo, la razón es capaz de discernir entre los varios bienes que atraen a la voluntad.

${ }^{59}$ Véase Santo Tomás de Aquino, Summa theologiae I-II, q. 94, a. 2.

${ }^{60}$ Véase ibid., ad. 3.

${ }^{61}$ Véase Summa theologiae I-II, q. 6, a. 1, ad. 3. Así como la razón no puede controlar las funciones biológicas involuntarias, tampoco puede determinar la orientación natural de los apetitos racionales: el hombre no puede sino querer su propia felicidad. Aunque es "dueña de su acto" (domina sui actus) -en oposición a "lo que viene determinado por una cosa (determinata ad unum) (Summa theologiae I-II, q. 1, a. 5)- la voluntad humana "tiende natural (y necesariamente) a su bien último; puesto que todo hombre naturalmente quiera la felicidad: $y$ todos los otros deseos son causa de este deseo natural; puesto que todo lo que un hombre quiere lo quiere en orden a un fin" (Summa theologiae I-II, q. 60. A. 2: "Unde voluntas naturaliter tendit en suum finem ultimum. Omnis enim homo naturaliter vult beatitudinem; et ex hac naturali voluntate causantur omnes aliae voluntates, cun quidquid homo vult, velit propter finem). Véase también idem, I-II, q. 91, a. 2, ad. 2. Para un desarrollo completo de esta tesis de la enseñanza de Santo Tomás, véase David M. Gallaher, "Desire for Beatitude and Love of Friendship in Aquinas", Medieval Studies, 58 (1996), pp. 1-47.

${ }^{62}$ Véase Tomás de Aquino, Summa theologiae I-II, q. 17, a. 5; q. 10, a. 1.

${ }^{63} \mathrm{Ibid}$., I, q. 62, a. 1: "Bajo el nombre de beatitud se comprende la perfección última de la naturaleza racional o intelectual; y por tanto es lo naturalmente deseado, pues todo desea naturalmente alcanzar su perfección última" ("nomine beatitudine intelligitur ultima perfectio rationalis seu intellectualis naturae: et inde est quod naturaliter desideratur, quia unumquodque naturaliter desiderat suam ultimam perfectionem”). Véase también Summa theologiae I-II, q. 10, a. 1., ad. 1; y I, q. 60, a. 3. 
Como Santo Tomás, Badinter sostiene que los seres humanos deben actuar responsablemente. No obstante, para Badinter las mujeres son responsables de sus decisiones sobre la maternidad al otorgarse la primacía a sí mismas y a su deseo de una vida más placentera. En particular, una mujer actúa de forma más razonable cuando subvierte el "deseo" maternal que surge de su mera biología (y que también comparten otros animales) en favor de un deseo más auténticamente humano de vivir en sociedad: de tener actividad en el mundo, fuera del hogar donde se dice que es la esclava de sus hijos. En contraste, mientras que Santo Tomás ciertamente recomendaría seguir las inclinaciones racionales por encima de los meros impulsos biológicos, también contendería que las prácticas intrínsecas a la maternidad (el acto sexual, el alumbramiento y la crianza) siempre son emprendidas por los seres humanos en tanto que son agentes racionales: por tanto, la práctica de la maternidad siempre es una actividad racional, por lo menos parcialmente.

Numerosas mujeres contemporáneas tienden al acuerdo con Santo Tomás; en contra de Badinter, es difícil suponer que la mayoría de las mujeres tengan en mente el acto biológico de concebir una vida al mencionar su instinto maternal, que es más que simples ganas de copular. ${ }^{64}$ El deseo maternal tampoco suele ser entendido ( $\mathrm{y}$ tan solo pensar que pudiera entenderse así suena ridículo) como el deseo de contribuir al crecimiento de la población o de colaborar en la conservación de la especie, ni siquiera (al menos no en la mayoría de los casos) de preservar el nombre, la "sangre" o las heredades de una familia. Hay algo profundamente más humano, por decirlo de alguna manera, en este deseo: algo que ciertamente la mayoría de las mujeres (por lo menos de quienes así lo admiten) comprenden que contribuye a su felicidad y plenitud personales, si bien de forma secundaria o refleja. El verdadero objeto de este deseo no es (y aquí nos atrevemos a diferir de Badinter) la felicidad de una mujer, ni siquiera su placer; lo cual no significa negar

${ }^{64}$ Daphne de Marneffe lo expresa de manera muy práctica cuando escribe: "El sentido común dicta que 'madre' y 'deseo' no caben en la misma oración. Se nos ha dicho que el deseo toca al sexo. Se nos ha dicho que la maternidad toca a todo menos al sexo"; loc. cit. Véase también Cristina L. H. Traina, Feminist Ethics and Natural Law: The End of the Anathemas, 1999, Washington D.C., Georgetown University Press. 
que pudiera haber cierta correspondencia entre ambos. ${ }^{65} \mathrm{Su}$ verdadero objeto es un niño o unos niños; ${ }^{66}$ dicho esto, vuelvo a la pregunta inicial: ¿cómo es que alguien querría ser madre si no es por amor?

\section{Maternidad y amor: ¿tienen algo que ver?}

Al responder a esta importante pregunta, uno pudiera comenzar por admitir ante Badinter que las mujeres bien pueden ser engañadas para que acepten ser madres, por medio de la culpa aunada a la coerción y las expectativas sociales, que muy a menudo han sido presentadas en forma de obligaciones morales; sin embargo, resulta evidente que esto no es lo que ella ni yo queremos decir por libre elección de la maternidad. Más aún, a mi pregunta (“¿cómo es que alguien quisiera ser madre si no es por amor?") también pudiera ponerse como objeción que resulta imposible hablar de amor cuando hay deseo, precisamente porque el segundo (el deseo maternal) precede a la realidad (el hecho de ser madre). Como atinadamente lo hace notar Santo Tomás: "El deseo implica la ausencia real del amado"; 67 sin embargo, en el caso que nos ocupa el amado (un futuro vástago) no solamente está ausente, sino que es incapaz de hacerse presente como objeto de un deseo. Haciendo de lado la cuestión de que si realmente buscamos el bien de los hijos

${ }^{65}$ Como bien lo dice Daphne de Marneffe: "Numerosas madres se sienten desgarradas por adentro cuando se separan de sus bebés y sus hijos durante muchas horas del días, aunque se sienten realistas o maduras cuando son capaces de reprimir estos sentimientos. Los términos de la discusión no admiten la posibilidad de que el placer sea una guía confiable, ni que el deseo nos revele cuál sea la verdad" (Maternal Desire, p. 13).

${ }^{66}$ Marie-Joseph Nicolas tiene buenas razones para decir, al referirse a Santo Tomás de Aquino, que "la intención de la naturaleza en la sexualidad humana no es como la de la sexualidad animal, preservar la especie: es procrear una persona humana significativa por sí misma (etiam individua sunt de principali intentione naturae) y por consecuencia conducirle a su plena estatura y autonomía por medio de la educación" (Marie-Joseph Nicolas, "L'idée de nature dans la pensé de saint Thomas d'Aquin", Revue thomiste, 74, núm. 4 (1974), p. 571: "l'intention de la nature dans la sexualité humaine n'est pas comme dans la sexualité animale de sauvedarder l'espèce: elle es te procréer une personne humaine qui vaut pour elle-même (etiam individua sunt de principali intentione naturae) et par conséquent de la mener jusqu'à sa pleine stature et autonomie par l'éducation"). Cfr. Tomás de Aquino, Summa theologiae, I, q. 98, a. 1.

${ }^{67}$ Tomás de Aquino, Summa theologiae I-II, q. 28, a. 1, ad. 1. 
ya nacidos por encima de nuestro propio bien, después de todo la pregunta se reduce a saber si las mujeres naturalmente desean traer niños a la existencia en colaboración con el Creador. ¿Cómo es que se puede amar a un hijo que solamente existe en la imaginación?

Esta objeción sirve sobremanera como introducción a mi respuesta para la primera pregunta: ¿es que las mujeres naturalmente desean procrear? Precisamente al invocar al amor como el motivo para la maternidad, tengo en mente una definición clásica de esta noción (el amor), a saber, aquello cuyo objeto (en este caso, el hijo) está presente no solo como el fruto (o fin) del deseo, sino también desde su origen, como eso que da nacimiento al deseo. ${ }^{68}$ "El fin se corresponde con el principio", ${ }^{69}$ piensa Santo Tomás, porque el bien (el objeto de nuestro deseo) tiene aspecto de fin. ${ }^{70}$ En otras palabras, es la meta que persigue el deseo. Ciertamente, como lo explica Jan Aersten, "un movimiento hacia un fin solamente es posible cuando de cierta manera este determina el movimiento". ${ }^{71}$ En consecuencia, hay un "comienzo del fin" (inchoatio finis), ${ }^{72}$ una como orientación de la cual podría decirse que de algún modo determina el movimiento hacia el fin en el sujeto que lo desea. Para ponerlo en otros términos, debajo de cada deseo hay una "anticipación unitiva" ${ }^{\text {"73 }}$ o afinidad ${ }^{74}$ (lo que Tomás llama "conna-

${ }^{68}$ Véase como ejemplo H. D. Simonin, “Autour de la solution thomiste du probléme de l'amour," Archives d'histoire doctrinale et littéraire du moyen age, 1932, París, Vrin, 6 (1931), pp. 174-274.

${ }^{69}$ Cfr. Summa theologiae I-II, q. 2, a. 5, ad. 3: "Quia finis respondet principio". Cfr. ibid., q. 26 , a. 2 ; q. 1 , a. 4.

${ }^{70}$ Summa theologiae I-II, q. 25, a. 2: "Bonum autem habet rationem finis". Véase también cap. II ("La doctrine de l'amour et la causalité finale") of H. D. Simonin, "Autour de la solution thomiste du problème de l'amour," pp. 199-245.

${ }^{71}$ Jan Aersten, Nature and Crature, p. 343. En consecuencia, incluso si se considera correctamente que el fin es lo que viene al último en el orden de ejecución (y de ahí su nombre), es lo primero en el orden de la intención. Véase Summa theologiae, I-II, q. 28, a. 1.

${ }^{72}$ Se hace referencia a Santo Tomás de Aquino, De Veritate 14, 2.

${ }^{73}$ Jan Aertsen, Nature and Creature, 343. Véase también Tomás de Aquino, Summa theologiae I-II, q. 28, a. 1.

${ }^{74}$ En otras palabras, el amor presupone cierta semejanza en virtud de la cual el amado puede ser considerado como un "ser". Véase por ejemplo, Summa theologiae I, q. 60, a. 4. O como lo explica Josef Pieper haciendo referencia al desarrollo etimológico del término "el amor incluye y se basa sobre una relación preexistente entre el amante y el amado" ("On Love", p. 159). 
turalidad"75) entre una naturaleza y su objeto o el fin (el bien) ${ }^{76}$ hacia el cual tiende. Esto no significa que los deseos sean simplemente subjetivos (determinados por el sujeto) pues por el contrario es el objeto de nuestro deseo (el bien o el amado) lo que se dice es su causa. ${ }^{77} \mathrm{El}$ objeto amado, la persona amada (sea que esté presente o ausente, que sea real o imaginaria) causa las inclinaciones a las cuales nos referimos con la palabra deseo, al suscitar afecto hacia sí mismo, a lo cual el Aquinate llama amor (amor) o complacencia (complacentia). ${ }^{78} \mathrm{De}$ hecho, en tanto que somos criaturas racionales, nosotros actuamos especialmente por una causa o de acuerdo con nuestros deseos: queremos (y por tanto, elegimos) estar unidos con aquello a lo que amamos. En consecuencia, sabemos por propia experiencia que la intuición de Tomás es cierta: "el amor precede al deseo". ${ }^{79}$ Como atinadamente lo expresa Josef Pieper:

El amor es el principio subyacente del querer y aparece primero tanto en la sucesión temporal como el orden jerárquico. No solamente [...] el amor es por naturaleza el más temprano de los actos de nuestra voluntad, ${ }^{80}$ y no solamente todos los impulsos de la voluntad se derivan del amor, ${ }^{81}$ sino que el amor también inspira, como su principium, esto es, como su fuente inmanente, todas las decisiones específicas y hace que se sigan moviendo. ${ }^{82}$

${ }^{75}$ Literalmente, aquello que está en acuerdo o armonía con la naturaleza. Véase por ejemplo Tomás de Aquino, Summa theologiae I-II, q. 26, a. 2, c. y ad. 3.

76 "El bien ha sido bien definido como aquello hacia lo que apuntan todas las cosas (Aristóteles, Ética nicomaquea, I. 1. 109a1-3). "Queda claro que el bien tiene naturaleza de fin" (Tomás de Aquino, Summa theologiae I, q. 103, a. 2: "Manifestum est enim quod bonum habet rationem finis").

${ }^{77}$ Véase como ejemplo Summa theologiae I-II, q. 27, a. 1.

${ }^{78}$ Véase Summa theologiae I-II, q. 23, a. 4, en donde se alega que "el bien causa, en la potencia apetente, cierta inclinación, aptitud o connaturalidad con respecto al bien; y esto sucede con la pasión del amor. ("Bonum ergo primo en potentia appetitiva causat quamdam inclinationem, seu aptitudinem, seu connaturalitatem ad bonum, quod pertinet ad passionem amoris). Véase también ibid., q. 28, a. 2.

${ }^{79}$ Ibid., q. 25, a. 2. [“amor praecedit desiderium"] Véase también ibid., q. 28, a. 1.

${ }^{80}$ Véase Tomás de Aquino, Summa theologiae I, q. 20, a. 1.

${ }^{81}$ Véase ibid., I, q. 60, prólogo; I, q. 20; e idem, Summa Contra Gentiles I, 4, 19.

${ }^{82}$ Josef Pieper, "On Love", p. 166. De manera semejante, Servais Pinckaers afirma que: "El primer movimiento del 'apetito', en donde radica el origen de todos los movimientos y sigue continuamente presente en ellos, es el amor, que podemos definir como el deleite simple y directo en el objeto percibido y conocido como bien (obviamente este objeto y el bien que 
Por lo que toca al caso que nos ocupa (el "amor" que las mujeres sienten, por así decirlo, no solamente por los hijos que ya tienen sino también e incluso por hijos que aún no han sido concebidos), podríamos por tanto distinguir entre la "unión real" (secundum rem) entre el amante y el amado (mujer e hijo) o la "unión afectiva" (secundum affectum), ${ }^{83}$ que surge al percibir la unidad entre el objeto amado (en este caso, el niño) y el amante (la mujer que añora ser madre), lo cual produce el deseo (maternal).

Tal "unión afectiva" tiene como ventaja característica que responde a la objeción según la cual la idea del deseo maternal viola la dignidad de la mujer en tanto que implica una reducción biológica. Lo cierto es que, lejos de suponer un impulso biológico o una capacidad física para la maternidad, esta manera de concebir el deseo como aquello que surge del amor apela a la naturaleza racional de la mujer; esto es así porque no solo implica su poder de volición, sino también sus potencias intelectuales de entendimiento e imaginación: potencias que, por supuesto, comparte con el varón. Por otro lado, pudiera objetarse que mientras esta solución podría por tanto rescatar la dignidad de la mujer, difícilmente salva la dignidad del niño, quien aparentemente ha sido instrumentalizado, en tanto que se le invita al mundo como objeto de los sueños de su madre o de los proyectos que ella tiene para su superación personal. Por tanto, más allá de la cuestión del deseo maternal, nos encontramos ahora ante una cuestión todavía más importante: el amor en sí.

representa pueden ser una persona, como cuando se dice: tal o cual persona me da alegría, me intriga, me toca, etcétera). Distintas clases de amor se corresponden con distintas especies de deseo" (Servais Pinckaers, "The Natural Desire to See God", Nova et Vetera, 2010, 8, edición en inglés, núm 3, p. 639.)

${ }^{83}$ Summa theologiae I-II, q. 28, a. 1. Santo Tomás afirma con mayor particularidad que "cuando amamos una cosa, al desearla, la aprehendemos como algo que pertenece a nuestro bienestar. De cierta manera, cuando un hombre ama a otro con amor de amistad, le desea al bien tanto como se lo desea a sí mismo: por tanto, aprehende al otro como a su otro ser" "“cum enim aliquis amat aliquid, quasi concupiscens illud, apprehendit illud quasi pertinens ad suum bene esse. Similite cum aliquis amat aliquem amore amicitiae, vult ei bonum, sicut et sibi vult bonum; unde apprehendit eum ut alterum se"). 


\section{EI amor como potencia afirmativa}

Entonces podríamos preguntarnos qué es el amor en tanto que amor humano y en tanto que amor maternal. ¿A qué nos referimos al hablar con "sentido común" de una noción de amor maternal que (a pesar de que inevitablemente produce en la mente hasta de aquellos que no tuvieron una niñez feliz numerosas imágenes felices e incluso idealistas, de lo cual se vale Badinter para insistir en usar el término "mito") no puede ser definida con facilidad. Con demasiada frecuencia nos vemos tentados a salvar el amor del instinto presentándolo como un acto de la voluntad, con lo cual nos referimos a una decisión, a una elección, un compromiso o incluso un esuferzo. En suma, lo presentamos como una potencia activa, de donde proviene el término "fuerza de voluntad". Casi completamente ajena a este discurso (a menos, por supuesto, que nos estemos refiriendo al amor erótico o sexual), está la noción del amor como pasión, y en consecuencia, como algo sumamente receptivo hacia su objeto: el amado. En este sentido, el amor se comprende mejor, como ya lo ha afirmado Josef Pieper, como "una suerte de encantamiento que nos viene y nos sucede". ${ }^{84}$ Por tanto, tenía buenas razones para preguntar: “¿Quién, estrictamente hablando, es el sujeto activo cuando alguien nos 'agrada' o cuando nos encontramos con alguien 'encantador'?"85

A decir verdad, el amor de una madre inevitablemente es caracterizado por lo que Pieper admite que es lo propio del amor, a saber, "una sumisión que implica el olvido de uno mismo que resulta en 'no perseguir ninguna ventaja"". ${ }^{86}$ Desde este punto de vista, resulta obvio que el amor de una madre por su hijo se inclinará hacia un solo lado por un buen número de años. No obstante, el amor entendido en sentido pasivo como un encantamiento, se ve reciprocado mucho más pronto, incluso durante los primeros meses de vida del niño, como lo ilustra el teólogo suizo Hans Urs von Balthasar por medio de una imagen:

Después de que la madre ha sonreído a su hijo a lo largo de muchos días y semanas, por fin llega a recibir como respuesta la sonrisa del niño. Ha

${ }^{84}$ Josef Pieper, “On Love”, p. 163.

${ }^{85}$ Ibid., p. 153.

${ }^{86}$ Ibid., p. 163. 
despertado el amor en el corazón del niño, y conforme el niño va despertando, también despierta a la sabiduría: las impresiones que al principio estaban vacías de sentido van cobrando significando al agruparse en torno al núcleo del Tú. ${ }^{87}$

Por supuesto que si una sonrisa de gozo puede "producir" como respuesta otra sonrisa de gozo, ello me conduce a sugerir que es meramente el efecto o reconocimiento de una cierta "connaturalidad" entre la madre y el niño, una compatibilidad, una comunión apropiada ${ }^{88}$ (por ejemplo, los animales no sonríen), lo cual es un dato que viene dado desde el principio, sin haber sido creado por la voluntad humana. Al contrario, en este caso la función de la voluntad es precisamente la de afirmar o consentir, en lo cual insiste Pieper que es tan propio de la voluntad como aquello otro que suele ser aceptado con mayor frecuencia, cuando se dice que la voluntad es el acto de "decidir a favor de acciones con base en los motivos". En el primer caso, el acto de la voluntad se expresa mejor como "acuerdo, asentimiento, consentimiento, aplauso, afirmación, loa, glorificación y alabanza". ${ }^{89}$ De hecho, lejos de ejercer una neutralidad objetiva, la voluntad es "tocada" (o "llevada"), por decirlo de alguna manera, por el bien objetivo que representa la persona o el objeto amado, precisamente porque (y con esta idea volvemos al concepto de connaturalidad, proporcionalidad, correspondencia o conveniencia entre una naturaleza y su inclinación) "el amor no solamente genera y crea unidad", sino que presupone esta unidad: ${ }^{90}$ una unidad que, por así decirlo, simplemente está dada. En otras palabras (vale la pena repetirlo), antes de la unión real de los amantes (o, en el caso que nos ocupa, madre e hijo, aunque el mismo razonamiento pudiera aplicarse a padre e hijo), que produce gozo o placer, está la unión afectiva, a la cual Santo Tomás primero llama amor y después define a mayor profundidad como "complacencia en el bien" (complacentia

${ }^{87}$ Hans Urs von Balthasar, Love Alone is Credible, 2004, San Francisco, Ignatius Press, traducción de David C. Schindler, p. 76.

${ }^{88}$ Sobre este tema, véase elcapítulo 3 ("La similitude cause de l'amour") de H. D. Simonin, "Autour de la solution thomiste du problème de l'amour", pp. 246-70.

${ }^{89}$ Josef Pieper, "On Love”, p. 164.

${ }^{90}$ Ibid., p. 159. 
boni), que consiste en "una aptitud o proporción del apetito con respecto al bien" en virtud de la cual en cierto sentido uno ya se encuentra unido a aquello (o a aquel) hacia el que se inclina, pues uno ama a su semejante. ${ }^{92}$ Esto significa, como lo explica Michael Sherwin, que antes del amor hay un principio de acción, y este es una "respuesta al bien", 93 en particular cuando viene en forma de esa "agradable afinidad afectiva"94 que Santo Tomás llama complacentia (literalmente, "con deleitoso asentimiento", cum + placentia). O como lo expresaría Pieper, es la conciencia espontánea del bien que naturalmente afirma: “¡Es bueno que existas, es bueno que estés en el mundo!"95

Por supuesto que con esta hermosa reflexión nos encontramos de nuevo con la objeción previamente enfrentada con respecto al deseo maternal: ¿cómo es posible amar con amor espontáneo y afirmativo a un niño que todavía no existe (y que tal vez nunca lo haga)? Me parece que Pieper también proporciona una respuesta, al reconocer en estas gozosas palabras (; cuán bueno es que existas!) "una continuación y en cierto sentido incluso un perfeccionamiento de aquello que comenzó en el transcurso de la creación", ${ }^{96}$ esto es, cuando Dios miró lo que

${ }^{91}$ Tomás de Aquino, Summa theologiae I-II, q. 25, a. 2: "Ipsa autem aptitudo sive proprotio apetitus ad bonum est amor, qui nihil aliud est quam complacentia boni". Véase también ibid., q. 26, a. 2, e ibid., q. 28, a.1 c, ad. 2. En su estudio etimológico de la palabra "amor" en diversos idiomas, Pieper señala de forma interesante hacia "un elemento semántico largamente sospechado y casi conscientemente conocido: que el 'amor' incluye y se basa sobre una relación preexistente entre el amante y el amado" (Josef Pieper, "On Love”, p. 159). En consecuencia, no resulta sorprendente que Anna Williams reconozca como la "suposición básica" que ciñe al pensamiento de Santo Tomás sobre la caridad a "la intuición platónica de que el amor implica una especie de semejanza". (Anna Williams, The Ground of Union: Deification in Aquinas and Palamas, 1999, Nueva York y Oxford, Oxford University Press, p. 75).

${ }^{92}$ Ibid., p. 159.

${ }^{93}$ De manera más específica: "Es una respuesta a la bondad de Dios, a la solidaridad de las criaturas racionales con esta bondad, y a la bondad propia de las criaturas irracionales en el orden de su relación con Dios y de nuestra solidaridad con Él (Michael S. Sherwin, "Aquinas, Augustine and the Medieval Scholastic Crisis concerning Charity", en Aquinas the Agustinian, edición de Michael Dauphinais, Barry David y Matthew Levering, 2007, Washington DC, Catholic University Press, p. 199. Véase también idem, By Knowledge and by Love: Charity and Knowledge in the Moral Theology of Aquinas, 2005, Washington DC, Catholic University Press, en especial pp. 63-118.

${ }^{94}$ Sherwin especifica que "esta afinidad es la aptitud, inclinación o proporción que existe en el apetito hacia el objeto amado" (By Knowledge and by Love, p. 70).

${ }^{95}$ Josef Pieper, "On Love”, p. 164.

${ }^{96}$ Ibid., p. 172. 
Él había creado y proclamó que era "bueno” (cfr. Gn 1, 9, 12, 18, 21, 25) e incluso "muy bueno" (véase Gn 1,31). ${ }^{97}$ En otras palabras, “¡cuán bueno es que tú existas!" como afirmación fundamental, tal como lo explica Pieper, es "una imitación del acto creativo divino en virtud del cual todo ser humano [...] existe” y “es simultáneamente 'bueno', es decir, amable". ${ }^{98}$

Al enfrentar así el poder creativo de nuestro amor, Pieper tiene en mente (como lo veremos en las conclusiones) al bien que invoca desde el corazón del amado, tal que este puede en consecuencia reconocer su propio bien intrínseco y actuar de acuerdo con este, ${ }^{99}$ incluso hasta llegar al grado de amar en reciprocidad (para evocar la reflexión de Balthasar). No obstante, en el caso que nos ocupa (el de las mujeres llamadas a ser madres) parece particularmente apropiado recordar el poder creativo del amor humano en tanto que coopera (por medio de la procreación) con el poder creativo de Dios mismo. A decir verdad, hay un principio importante que no podemos violar al hacer la analogía entre el amor divino y el amor humano; a diferencia de la voluntad humana, movida por un bien pre-existente en las cosas, la voluntad divina crea el bien en cosas y personas. ${ }^{100}$ En consecuencia, ninguna mujer

${ }^{97}$ Véase ibid., pp. 177 y 178.

${ }^{98}$ Ibid., p. 274.

${ }^{99}$ Para comprender esto resulta útil otra imagen de Balthasar: "El amor es creativo con respecto al prójimo: produce una imagen suya que el amado no se hubiera adjudicado, y cuando el amor es fiel y genuino le da el poder de acercarse más a esta imagen y de asemejarse a ella. No quiere decepcionar; quiere mostrarse agradecido porque alguien se lo toma tan en serio y espera tanto de él" (Hans Urs von Balthasar, Convergences: To the Source of Christian Mystery, 1983, San Francisco, Ignatius Press, traducción de E. A. Nelson, pp. 128-9). Algo semejante afirma Juan Pablo II en su comentario a Efesios 5: "El bien que con su amor crea el amante en el amado es como la prueba y medida de ese amor" (Audiencia General del $1^{\circ}$ de septiembre de 1982; en Juan Pablo II, Man and Woman He Created Them: A Theology of the Body, 2006, Boston, Pauline Books, traducción y edición de Michael Waldstein, p. 484).

100 "Por tanto, puesto que amar algo no es sino desear su bien, es manifiesto que Dios ama todo lo que existe. Pero no como nosotros amamos. Porque puesto que nuestra voluntad no es la causa de la bondad de las cosas, sino que se ve movido con esta como su objeto, nuestro amor, por el cual le deseamos el bien a algo, no es la causa de su bondad; sino que de forma conversa su bondad, sea real o imaginaria, invoca a nuestro amor, por el cual queremos que conserve el bien que ya tiene, y que además reciba el bien que todavía no tiene, y hacia este fin es que dirigimos nuestras acciones: mientras que el amor de Dios infunde y crea la bondad." (Summa theologiae I, q. 20, a. 2: "Unde, cum amare nihil aliud sit quam velle bonum alicui, manifestum est quod Deus omnia quae sunt, amat; non tamem eo modo sicut núm. Quia 
debería engañarse a sí misma pensando que es capaz de verdaderamente crear el bien en sus hijos: su papel es el de pro-crear (de cooperar en la obra creativa de Dios). Sin embargo, ello significa que la mujer no solamente está facultada físicamente para recibir pasivamente la vida en su seno, como si allí la "plantara" el Creador, por decirlo de alguna manera. Lo cierto es que ella también está especialmente dotada con una capacidad racional en particular que comparte con los varones, la capacidad para escoger voluntariamente la vida. Con esto quiero decir no solamente que se abstiene de oponer obstáculos al desarrollo de una nueva vida en su seno, sino que de forma por demás positiva (y con mucha mayor dignidad) ella puede verdaderamente deleitarse en la concepción de un hijo, proclamando un eco del Creador: “¡Cuán bueno es que tú existas! ¡Cuán maravilloso es que te encuentres en el mundo!"

\section{Amor y realización personal}

El modo en que Pieper presenta al amor tiene la ventaja particular de señalar hacia la bondad intrínseca del amado (en este caso, el hijo), más que hacia cuán deseables o útiles pueden ser algunas de sus características específicas; con seguridad, cada uno de nosotros desea ser afirmado de esa manera más que ser "amado" de forma instrumental o por obligación o incluso deber. Por supuesto que el verdadero amante no puede responder a la pregunta: “Por qué me amas?” Si lo hiciera, correría el riesgo de instrumentalizar al amado. Más aún, así como la voluntad humana no es soberana al determinar el bien, nosotros tampoco somos "“soberanos' en el amor", ${ }^{101}$ como Pieper hace bien en insistir. No es nuestro amor lo que hace que alguien o algo sea amable. Por

enim voluntas nostra non est causa bonitatis rerum, sed ab ea movetur sicut ab objecto; amor noster, quo bonum alicui volumus, non est causa bonitatis ipsius; sed e converso bonitas ejus, vel vera, vel aestimata, provocat amorem, quo ei volumus et bonum conservario quod habet, et addi quod non habet; et tu ad hoc operemur. Sed amor Dei infundens et creans bonitatem en rebus". Véase también ibid., I-II, q. 110, a. 1, e idem, Ioan, V, lect. 3, núm. 753.

${ }^{101}$ Josef Pieper, "On Love”, p. 220. 
el contrario, nuestro amor es una estimación de la bondad intrínseca del amado.

Más allá de la ventaja significativa que nos brinda el concebir el amor como afirmación, está la unidad implícita entre el amor propio o la realización personal y el amor auténtico hacia alguien más; claro que este punto es de gran importancia al responder a las preocupaciones de Badinter. Después de todo ella asume (precisamente al exponer el egoísmo escandaloso de las mujeres a lo largo de cuatro siglos de cultura francesa, siempre que ese egoísmo era socialmente permitido) que de hecho ha destruido el "mito" del amor maternal, ${ }^{102}$ la idea de que una mujer puede verse "naturalmente" realizada a través de la maternidad. Badinter alega que si las mujeres buscan ser madres, ello no tiene nada que ver con la naturaleza ni con alguna inclinación natural, sino más bien con presiones socioculturales que surgen de un ideal según el cual la maternidad es considerada como el deber o el honor de una mujer. O bien, a falta de presiones como esas (conforme oscila el péndulo), se elige la maternidad por simples razones egoístas, tales como la búsqueda del placer o de alguna forma de realización personal. En consecuencia, en nuestros tiempos Badinter llega a decir, por ejemplo: "El individualismo y el hedonismo propios de nuestra cultura se han llegado a convertir en los motivos principales para reproducirse, pero también a veces en el motivo para no hacerlo". ${ }^{103}$

Como respuesta o argumento en contra, podríamos recurrir otra vez a las valiosas reflexiones de Pieper, desarrolladas principalmente en oposición a una forma protestante de presentar al amor (representada, por ejemplo, por Anders Nygren), ${ }^{104}$ de acuerdo con la cual se piensa que el amor propio y el amor al otro se oponen radicalmente. ${ }^{105} \mathrm{No}$ obstante, cuando se concibe al amor en el sentido ya expuesto, como

${ }^{102}$ Véase supra nota12.

${ }^{103}$ Le conflit, 10: "L'individualisme et l'hédonisme propres à notre culture sont devenus les premiers motifs de notre reproduction, mais parfois aussi de son refus".

${ }^{104}$ V. Anders Nygren, Agape and Eros, 1982, Chicago, University of Chicago Press, traducción de Philip S. Watson.

${ }^{105}$ Fergus Kerr tiene razones de peso para hacer notar que "algunos filósofos como Bernard Williams y Martha Craven Nusbaum, subidos al carro de una ética de la virtud, consideran que, al rechazar la ética kantiana del deber por el deber mismo, lo que están rechazando es la ética cristiana como tal" (After Aquinas, p. 116). 
consentimiento, aprobación o afirmación, entonces, de acuerdo con el razonamiento de Pieper, el gozo y la felicidad se entienden adecuadamente como "nuestra respuesta al participar de algo que amamos; y si la aprobación amorosa y sencilla de algo que amamos es algo amado de por sí, entonces debe ser igualmente cierto que nuestro deseo de felicidad puede ser satisfecho precisamente por tal afirmación dirigida hacia alguien más, esto es, por el amor 'altruista". ${ }^{106}$ En suma, "no hay brecha" que separe el amor que da del amor que afirma. ${ }^{107}$ Es más, Pieper presenta "la nostalgia de una existencia plena" como "aquello que se encuentra de forma cierta y legítima en la raíz de todo amor". ${ }^{108} \mathrm{De}$ hecho, Pieper sostiene que esta nostalgia no es "sino la dinámica elemental de nuestro ser mismo, que el acto que nos creó ha puesto en movimiento". ${ }^{109}$ En consecuencia, el deseo de ser feliz "no solamente está 'en orden' sino que es el comienzo indispensable de toda perfección en el amor". ${ }^{110} \mathrm{O}$ como lo afirma Marie-Joseph Nicolas: "En la vida, placer, alegría y espontaneidad no deben ser jamás rechazados, sino por el contrario deben ser alentados, puesto que son el signo del cumplimiento de la naturaleza, de la creación de Dios". ${ }^{111}$

${ }^{106}$ Josef Pieper, “On Love”, p. 241.

${ }^{107}$ Ibid., p. 242.

${ }^{108} \mathrm{Ibid}$., p. 208. Lo que aquí queda esbozado en forma de declaración es presentado por Pieper en forma de pregunta retórica. De ahí una formulación más directa: "El amor como necesidad, cuyo fin es su propia satisfacción, también está en el núcleo y en el comienzo de todos nuestros amores" (ibid., p. 222).

${ }^{109}$ Ibid., p. 222.

${ }^{110} \mathrm{Ibid}$., p. 223. Para consideraciones muy completes sobre este tema desde un punto de vista ético, véase Servais Pinckaers, The Sources of Christian Ethics; idem, The Pursuit of Happiness-God's Way: Living the Beatitudes, traducido por Sr. Mary Thomas Noble, 1998, Staten Island, NY, St. Pauls. Véase también Albert Plé, Par devoir ou par plaisir; David M. Gallagher, "Desire for Beatitude y Love of Friendship in Aquinas", Mediaeval Studies 58 (1996): 1-47; idem, "Goodness y Moral Goodness"; Craig Steven Titus, Resilience and the Virtue of Fortitude: Aquinas on Dialogue with the Psychosocial Sciences, 2006, Washington DC, CUA Press, especialmente pp. 98ss.; Michael Sherwin, "Happiness and Its Discontents"; Nicholas E. Lombardo, The Logic of Desire: Aquinas on Emotion, 2011, Washington, DC, CUA Press; y Denis J. M. Bradley, Aquinas on the Twofold Human Good. Reason and Human Happiness in Aquinas's Moral Science, 1997, Washington, DC, CUA Press, quien afirma que la voluntad es "fuente secundaria de la ley natural" (p. 323). "Para Santo Tomás, la ley natural tiene una fuente en el intelecto y otra en los apetitos; a pesar de que la segunda es secundaria y subordinada, ambas deben considerarse siempre" (ibid., p. 325).

${ }^{111}$ Marie-Joseph Nicolas, "L'Idée de nature dans la pensée de saint Thomas d'Aquin", p. 569: "Le plaisir, la joie, la spontanéité de la vie ne sont absolument pas à rejeter comme tels, bien au contriare, pluisqu'ils sont le signe d'un accomplissemnt de la nature, de la création de Dieu". 
Desde este punto de vista, una mujer puede, por así decirlo, chiflar y comer pinole, pues no hay disparidad alguna entre el gozo auténtico de ser madre y el amor auténtico hacia sus hijos, ni tampoco entre la felicidad que surge de amar a su hijo y su propia plenitud personal. ${ }^{112}$ ¡Y todo esto sin necesidad de hacer referencia a biberones, guarderías, pañales ni padres concienzudos! Por supuesto, Badinter no deja de señalar atinadamente una cuestión, y es que de ninguna manera debemos menospreciar los sacrificios verdaderos y reales que entraña la maternidad (de donde proviene la validez de su argumento a favor de aligerar la carga por medio de las ayudas ya mencionadas), a pesar de que esto no necesariamente conduce a sus conclusiones, de acuerdo con las cuales, para que haya una maternidad satisfactoria, se requiere desde el principio una decisión basada sobre un cálculo realista de costos y beneficios. ${ }^{113}$ Más aún, podemos aplaudir su protesta ante la visión femenina de Rousseau (en la medida de que su interpretación del pensamiento de este sea verdadera) como algo "masoquista por definición". ${ }^{114}$ En fin, no podemos sino aborrecer la idea de que el significado de la existencia de una mujer estriba en su abnegación más que en su realización, algo que Badinter sostiene campeó por sus fueros durante buena parte de la historia de Francia.

En el sacrificio del ser, la mujer encontraba a la vez placer y una razón para existir. Ciertamente la madre era una masoquista. Más tarde, el aspecto religioso de su función iba a recibir un mayor énfasis, pero esta vez con la intención de echar luz sobre las dificultades que las mujeres encuentran regularmente. Las buenas madres no se materializaban solamente porque la sociedad las invocara. Fue necesario que hubiera un conjunto

${ }^{112}$ Con respecto a la sexualidad humana, Marie-Joseph Nicolas expresa algo semejante: “aquello que es propiamente humano en la sexualidad, que rebasa el fin animal 'genérico' de la procreación, no es tan solo convertir la 'procreación en un acto personal que se dirige hacia la persona, sino que por medio de ese acto uno alcanza la plenitud propia y la de la pareja: fines humanos específicos y secundarios" (Marie-Joseph Nicolas, "L'Idée de nature dans la pensée de saint Thomas d'Aquin", p. 572: “ce qui est proprement humain dans la sexualité, ce qui dépasse la fin 'générique', animale, de la procréation, ce n'est pas seulement de faire de la 'procréation' un acte personnel et visant la personne, mais, grâce à elle, de se réaliser soi-même et de réaliser le couple, fins secondaires mais spécifiquement humaines").

${ }^{113}$ Véase como ejemplo, Le conflit, p. 25.

${ }^{114}$ Mother Love, p. 232 [L'amour en plus, p. 319]. 
de valores espirituales cristianos para pavimentar la aceptación del autosacrifico, lo cual elevó a la buena madre por encima de su condición humana, espontáneamente egoísta. El enorme esfuerzo requerido para sobreponerse a su estado defectuoso la convirtió en una santa. ${ }^{115}$

$\mathrm{Si}$, por lo contrario, el camino para la perfección de los hombres ( $j$ sin importar el sexo!) es el amor con todos sus sacrificios y sinsabores, entonces esto es así únicamente porque el gozo del amor nos ayuda a soportarlos, como lo sugieren Santo Tomás y Pieper. Así pues, ni siquiera para un cristiano lo principal no es "dar hasta que duela", ${ }^{116}$ como lo proponía la beata madre Teresa de Calcuta. Antes bien, como lo expresa Pieper, el amante "después de todo se sale con la suya, pues obtiene como recompensa el amor". ${ }^{117}$ Y para un cristiano esto ciertamente implica el gozo de haber obtenido la perla de gran precio, que vale mucho más de lo que cuesta. Pieper sugiere que es muy cierto que incluso en el caso del amor sobrenatural o caridad, no es el sacrificio lo que viene primero, sino el gozo que surge de amar y ser amado en respuesta. ${ }^{118}$

La alegría del amor de ida y vuelta apunta hacia una consideración final, que llevará a nuestras conclusiones más allá del punto donde meramente se resuelve el conflicto entre el desarrollo personal y el amor o, como lo dice Badinter, entre "la mujer" y "la madre". Esto es así porque, al hablar del amor que es devuelto (como en el caso del niño que sonríe a su madre) hemos traspasado el dominio de la perfección personal. Precisamente mediante este ejemplo es que podemos hablar de un amor que perfecciona al amante y también al amado. Pieper no tiene la menor duda para enfrentar este misterio en términos de la

${ }^{115}$ Ibid. pp. 232, 235. [L'amour en plus, pp. 318-319].

${ }^{116}$ Véase como ejemplo madre Teresa of Calcuta, "Address to the National Prayer Breakfast", 1994, Washington D.C., 3 de febrero, publicado en Crisis (marzo de 1994), pp. 17-9; y en Matthew Levering (ed.), On Marriage and Family: Classic and Contemporary Texts, 2005, Lahnam, Boulder, Nueva York, Toronto, Oxford, Sheed and Ward / Rowman and Littlefild.

${ }^{117}$ Josef Pieper, “On Love”, pp. 244-5.

${ }^{118}$ De hecho, Pieper afirma que el amor "por naturaleza", esto es, "en virtud de la creación" está "tan íntimamente imbricado" con el amor sobrenatural o caridad que "no se pueden notar las costuras. O no por lo menos mientras se encuentren en mutua armonía los tres impulsos, el que surge de la naturaleza, el que surge de la libertad y el que surge de la gracia. Si remas en un bote siguiendo la dirección del viento, ¿cómo has de distinguir entre el movimiento causado por tu propio esfuerzo y aquel causado por el viento?" (ibid., p. 242). Véase también ibid., pp. 260,277 y 280 . 
continuación de la obra de la creación (como ya lo mencioné) cuando Dios proclamó que aquello que había llamado a la existencia era "bueno" e incluso "muy bueno". ${ }^{119}$ Con esto, el renombrado filósofo alemán quiere decir que el Creador nos ha equipado con un dinamismo intrínseco en forma de ciertas inclinaciones naturales, que nos llevan a desear el bien y por tanto nos perfeccionan, pero también quiere decir mucho más; de ahí la enseñanza tomista acerca del proceso de la creación, que no está completo hasta que no hayamos vuelto efectivamente (reditus) hacia Dios, perfeccionados en la virtud. ${ }^{120}$ A decir verdad, Pieper admite (haciendo referencia a Platón) que el amante es "más divino"121 que el amado, pero también insiste en que "ser capaz de amar sin depender de que el amor sea devuelto" es "un privilegio divino". ${ }^{122}$ Por otra parte, no duda en afirmar:

Más que existir apenas lo que necesitamos es ser amados por otra persona. Esto es un hecho que al considerarlo en profundidad nos deja estupefactos. Pareciera que no nos basta con haber sido creados por Dios; el hecho de la Creación necesita ser continuado y perfeccionado por el poder creativo del amor humano. ${ }^{123}$

Esta declaración (verdaderamente asombrosa) exige que el poder creativo se sostenga solamente sobre la afirmación, pues en el momento en que empezamos a pensar que nuestro amor tiene el poder de hacer amable al amado, de hecho hemos dejado de amar, pues en ese momento hemos dejado de afirmar al amado en la profundidad de su ser, precisamente tal como es. Con razón Shakespeare insiste: "Amor

${ }^{119}$ Véase ibid., p. 172.

${ }^{120}$ Véase Tomás de Aquino, Summa contra Gentiles, III, 20, 8; idem, Summa theologiae I, q. 6, a. 3; y Oliva Blanchette, "The Logic of Perfection en Aquinas," en David M. Gallagher (ed.), Thomas Aquinas and His Legacy, 1994, Washington DC, CUA Press, pp. 107-130.

${ }^{121}$ Se hace referencia a Platón, Symposium 180 b.

${ }^{122}$ Pieper, "On Love", p. 184.

${ }^{123}$ De manera por demás interesante, Badinter admite lo mismo al argumentar: "Contrario a lo que quisieran que creyéramos, el amor no está dado y ya, ni siquiera el amor de una madre por unos hijos que, ya adultos, no tienen nada que ofrecer a unos progenitores deficientes. De hecho, uno no puede dar sino lo que ha recibido..." (Le conflit, p. 253: "Contrairemente à ce que l'on veut nous faire croire, làmour ne va jamais de soi, même celui de la mère à l'égard des enfants, lequels, devenus adultes, n'ont rien à rendre à leurs parents déficients. En effet, on ne peut donner que ce que l'on a recu...") 
no es amor cuando se altera al encontrar alteración / o se somete a ser destruido por el destructor. No. Es un norte fijo para siempre que desafía las tempestades sin doblegarse jamás". ${ }^{124}$

Ese es el amor en el concepto de Pieper (y, como lo sugiere Shakespeare, en el de todos los amantes de verdad) y, tristemente, ese es el amor cuestionado por el argumento de Badinter. Al negar los afectos naturales de las madres hacia sus hijos, a fin de cuentas y para ser más específicos, no solamente nos advierte (muy atinadamente) contra el sacrificio de las mujeres en aras de la "diosa" Madre Naturaleza o los caprichos de las expectativas sociales. Al argüir que el amor por los hijos no surge espontáneamente del corazón de una madre, Badinter está cuestionando el fundamento mismo del argumento que podría utilizarse para obtener no solamente esos objetivos legítimos y buenos, sino también el objetivo de Pieper, que es prevenir una división inhumana entre el amor propio y el amor a otro, e incluso (mucho más importante todavía) la unidad intrínseca entre la dignidad inalienable de toda persona humana y el amor humano natural, que le afirma espontáneamente en esa dignidad. El único amor humano verdaderamente "creativo" en el sentido que Pieper da al término es el amor que responde. Cualquier otro "amor" humano es destructivo.

Tal es la opción fundamental que se abre ante cada mujer: una opción que posee mucho mayor significado que aquel planteado por Badinter, en que la mujer debe escoger entre la identidad de mujer o la de madre. Más específicamente, esta es la opción que decide cuál será el significado que la mujer dará a su amor, conforme a lo que Pieper (haciendo referencia a San Agustín de Hipona) ${ }^{125}$ expresa magistralmente al decir, "sea para bien o para mal, todo hombre vive para el amor. Es su amor y nada más lo que debe estar 'en orden' para que la persona como un todo sea 'recta' y buena". ${ }^{126}$ Por supuesto, esta opción también implica con quién nos aliamos, si con la opinión independiente y egoísta de Elisabeth Badinter, con la Madre Naturaleza o, como he afirmado que es lo más propio, con Nuestro Dios, Padre y Creador.

${ }^{124}$ William Shakespeare, soneto 116.

${ }^{125}$ San Agustín, Contra Faustum, 5,10, Migne, PL, vol., 42, 228: "quia ex amore suo quisque vivit, vel bene vel male".

${ }^{126}$ Josef Pieper, “On Love”, p. 166. 
CITAM Derechos Reservados.

La reproducción total o parcial de este artículo se podrá hacer si el ITAM otorga la autorización previamente por escrito. 